\title{
Percepção dos profissionais que atuam na Harmonização Energética Emergencial
}

\author{
Perception of professionals working in Emergency Energy Harmonization \\ Percepción de los profesionales que trabajan en la Armonización Energética de Emergencia
}

Recebido: 12/09/2021 | Revisado: 17/09/2021 | Aceito: 18/09/2021 | Publicado: 19/09/2021

\author{
Mariane Elivânia Silva \\ ORCID: https://orcid.org/0000-0002-9025-3380 \\ Universidade Federal do Rio Grande do Norte, Brasil \\ E-mail: marianeel30@gmail.com \\ Verbena Santos Araújo \\ ORCID: https://orcid.org/0000-0002-3519-4744 \\ Universidade Federal do Rio Grande do Norte, Brasil \\ E-mail: verbena@ufrn.edu.br \\ Isabel Cristina Amaral de Sousa Rosso Nelson \\ ORCID: https://orcid.org/0000-0003-4840-6950 \\ Universidade Estadual do Rio Grande do Norte, Brasil \\ E-mail:Isabelrosso@uern.br \\ Micheline Veras de Moura \\ ORCID: https://orcid.org/0000-0001-8519-637X \\ Hospital Universitário Onofre Lopes, Brasil \\ E-mail: michelineverasenf@gmail.com \\ Fernanda Maria Chianca da Silva \\ ORCID: https://orcid.org/0000-0002-2700-8390 \\ Universidade Federal da Paraíba, Brasil \\ E-mail: fernanda.silva@academico.ufpb.br \\ Lannuzya Veríssimo Oliveira \\ ORCID: https://orcid.org/0000-0002-6881-898X \\ Universidade Federal do Rio Grande do Norte, Brasil \\ E-mail:Lannuzya@gmail.com \\ Bianca Nunes Guedes do Amaral Rocha \\ ORCID: https://orcid.org/0000-0003-3312-9962 \\ Universidade Federal do Rio Grande do Norte, Brasil \\ E-mail: bianca.guedes@gmail.com
}

\section{Resumo}

Objetivo: Conhecer percepção dos profissionais sobre o atendimento de Harmonização Energética Emergencial de um serviço de práticas integrativas e complementares em saúde. Método: Trata-se de um estudo descritivo e qualitativo que utilizou como referencial metodológico a Pesquisa Convergente Assistencial e teve como cenário o Laboratório de Prática Integrativas e Complementares da Universidade Federal do Rio Grande do Norte, em especial o atendimento de Harmonização Energética. A coleta de dados ocorreu no período entre os meses de abril a junho de 2021.Foram realizadas entrevistas semiestruturadas, via Google Meet, com duração média de 30 minutos, com o intuito de investigar a compreensão dos profissionais sobre o atendimento de Harmonização Energética. Para organização e análise dos dados optou-se pelo método do Discurso do Sujeito Coletivo, os depoimentos coletados foram metodologicamente tratados por meio do software DSCsoft20. Resultados: Participaram 10 profissionais, sendo 01 servidor efetivo do serviço e 09 terapeutas voluntários. As principais ideias extraídas das entrevistas foram: Relação especial com as práticas integrativas, relação do serciente, terapeutas com essas práticas; Experiência do terapeuta com as práticas do Reiki e da Massagem; Práticas integrativas para o autodesenvolvimento do terapeuta, práticas integrativas como estratégia de promoção do bemestar do serciente; principais dificuldades e fragilidades do atendimento de Harmonização Energética e sugestões de melhorias. Conclusão: Os discursos presentes nesse trabalho, destacaram a importância da Harmonização Emergencial para os profissionais que atuam nesse serviço, despertando a reflexão a respeito do processo, apontando as oportunidades de crescimento, destacando também as fragilidades presentes no serviço, assim como, apontando sugestões de melhoria para que essa atividade seja desenvolvida da melhor forma.

Palavras-chave: Terapias complementares; Capacitação profissional; Gestão em saúde.

\footnotetext{
Abstract

Objective: To know the perception of professionals about the emergency energy harmonization of an integrative and complementary health practices service. Method: This is a descriptive and qualitative study that used convergent care research as a methodological framework and had as a scenario the Integrative and Complementary Practice Laboratory of the Federal University of Rio Grande do Norte. Data collection occurred between April and June 2021.Semi-structured interviews were conducted, for Google Meet, with an average duration of 30 minutes, to investigate the professionals' understanding of energy harmonization care. For data organization and analysis, the Collective Subject Discourse method
} 
was chosen, the collected statements were methodologically treated using the Software DSCsoft20. Results: 10 professionals participated. The main ideas extracted from the interviews were: Special relationship with integrative practices, relationship of the Serciente, therapists with these practices; Therapist experience with Reiki and Massage practices; Integrative practices for the therapist's self-development, integrative practices as a strategy to promote the wellbeing of the Serciente; difficulties and weaknesses of energy harmonization and suggestions for improvements. Conclusion: The discourses present in this work highlighted the importance of Emergency Harmonization for professionals working in this service, awakening reflection about the process, pointing out the opportunities for growth, also highlighting the weaknesses present in the service, as well as pointing out suggestions for improvement so that this activity is best developed.

Keywords: Complementary therapies; Professional training; Health management.

\section{Resumen}

Objetivo: Conocer la percepción de los profesionales sobre la armonización energética de emergencia de un servicio integrador y complementario de prácticas sanitarias. Método: Se trata de un estudio descriptivo y cualitativo que utilizó como marco metodológico la investigación asistencial convergente y tuvo como escenario el Laboratorio de Práctica Integrativa y Complementaria de la Universidad Federal de Rio Grande do Norte. La recolección de datos ocurrió entre abril y junio de 2021.Se realizaron entrevistas semiestructuradas, a través de Google Meet, con una duración promedio de 30 minutos, con el fin de investigar la comprensión de los profesionales de la atención de armonización energética. Para la organización y análisis de los datos, se eligió el método del Discurso Del Sujeto Colectivo, las declaraciones recogidas fueron tratadas metodológicamente utilizando el Software DSCsoft20. Resultados: Participaron 10 profesionales. Las principales ideas extraídas de las entrevistas fueron: Relación especial con las prácticas integradoras, relación de los Sercientes, terapeutas con estas prácticas; Experiencia del terapeuta con prácticas de Reiki y Masaje; Prácticas integradoras para el autodesarrollo del terapeuta, prácticas integradoras como estrategia para promover el bienestar del Serciente; dificultades y debilidades de la armonización energética y sugerencias de mejora. Conclusión: Los discursos presentes en este trabajo destacaron la importancia de la Armonización de Emergencias para los profesionales que trabajan en este servicio, despertando la reflexión sobre el proceso, señalando las oportunidades de crecimiento, destacando también las debilidades presentes en el servicio, así como señalando sugerencias de mejora para que esta actividad se desarrolle mejor. Palabras clave: Terapias complementarias; Formación profesional; Gestión de la salud.

\section{Introdução}

As Práticas Integrativas e Complementares em Saúde (PICS) compõe estratégias que utilizam tecnologias leves e eficazes que estimulam os mecanismos naturais de prevenção de agravos e recuperação visando realizar a interação homem-ambientesociedade estimulando o cuidado integral, em especial, o autocuidado (Brasil, 2006).

As PICS estão disponíveis para o uso da população, oficialmente, a partir da publicação da Política Nacional de Práticas Integrativas e Complementares (PNPIC)em maio de 2006, onde inicialmente foram disponibilizadas 05 práticas, sendo elas: Medicina Tradicional Chinesa (MTC), acupuntura, plantas medicinais, fitoterapia, homeopatia e termalismo/crenoterapia, posteriormente ocorreu a ampliação para mais 14 práticas e atualmente conta com 29 PICS regulamentadas pelo Sistema Único de Saúde (SUS)(Assis,2018).

Diversos estados vêm regulamentando suas políticas em PICS, sendo um deles o estado do Rio grande do Norte (RN), que aprovou a política de PICS em julho de 2011, sendo esta regulamentada em 21 de junho de 2021, através da lei 10.933 sua Política Estadual de Práticas integrativas e Complementares (PEPIC), disponibilizando a sociedade 32 práticas, ampliando além do proposto na política nacional de PICS (RN, 2021).

Outro avanço para a inserção das PICS no estado do RN foi a regulamentação da política de Práticas Integrativas do Município de Natal aprovada através da portaria 291 de 06 de junho de 2017 que além de regulamentar sua política, implantou de um serviço especializado em PICS o Centro de Práticas Integrativas e Complementares (CERPIC) (Natal, 2017).

No contexto acadêmico, a Universidade Federal do Rio Grande do Norte (UFRN), dispõe do Laboratório de Práticas Integrativas e Complementares - LAPICS/UFRN. O serviço funciona como um ambulatório especializado em PICS desenvolvendo atividades de ensino, pesquisa, extensão e atenção. Atende à demanda de usuários encaminhados pelo Hospital Universitário Onofre Lopes (HUOL), demanda espontânea dos usuários do Sistema Único de Saúde (SUS) e comunidade acadêmica. (Sampaio, 2017). 
No LAPICS/UFRN aquelas pessoas que participam das atividades do serviço são denominadas Sercientes, termo que surgiu de forma inédita, trazendo o sentido amplo do ser humano enquanto ser de consciência (Bezerra, 2019). Esse termo será utilizado no decorrer desse trabalho.

No serviço são ofertadas diversas PICS tendo como principal atividade o Protocolo de Acolhimento Integrativo Humanescente (PAIH) que foi organizado de forma inédita, tendo como premissa um fluxo e processo diferenciado de atendimento, tendo como objetivo o cuidado integrativo em saúde. O PAIH consiste nas seguintes etapas: Avaliação da Saúde Integral; Diagnóstico energético (Técnica de radiestesia com o uso do pêndulo); Pontos de Auriculoterapia para equilíbrio energético; escalda-pés terapêutico e Meditação visualizada (Bezerra,2019).

Os usuários atendidos pelo LAPICS seguem um fluxo de acordo com uma avaliação inicial realizada no Acolhimento Integrativo Humanescente. Após isso poderão ser direcionados para atendimento individual, práticas coletivas como Pilates e Yoga ou para o atendimento de Harmonização Energética Emergencial (HEE).

Uma das atividades realizadas no serviço é o atendimento de HEE que se caracteriza por ser uma atividade de promoção do reequilíbrio energético a partir da utilização das práticas do Reiki e da massagem. Segundo FREIJAT (2015), o Reiki equilibra harmoniosamente todos os aspectos do ser do receptor, de acordo com suas necessidades e desejos pessoais. Já a massagem pode ser aplicada com fins terapêuticos, servindo para ajudar no restabelecimento do equilíbrio das diversas estruturas humanas. A sua aplicação desencadeia efeitos mecânicos, analgésicos, psicológicos, térmicos e estruturais (Alves,2015).

Essas duas práticas integrativas foram escolhidas para serem trabalhadas no HEE, pois resultados de estudos científicos importantes demonstram que quando se associa Reiki a massagem é possível reduzir os níveis de estresse, quando comparado essas práticas realizadas separadamente sendo, portanto, técnicas bastante eficazes para minimizar os problemas mais comuns apresentados pelos usuários do LAPICS (Kurebayashi,2016).

A HEE é realizada em uma sala própria, no âmbito dentro do LAPICS, desde 2018, denominada de Harmonia, onde o Serciente, que passou pelo PAIH e foi detectado com qualquer tipo de desequilíbrio resultante de sobrecargas físicas, emocionais e/ou energéticas é atendido de forma imediata, funcionando como uma espécie de "pronto-atendimento". No processo de HEE estão incluídas as seguintes práticas: Reiki e Massagem, processos esses que são importantes para o restabelecimento da saúde desse Serciente, que buscou atendimento no LAPICS. Foram capacitados profissionais para atuarem especificamente nessas atividades (Sampaio, 2018).

A equipe do LAPICS/UFRN é composta por 65 membros, desses 59 atuam de forma voluntária no serviço, além disso, conta também com uma equipe de servidores efetivos da UFRN, porém em quantidade reduzida, apenas 06 servidores, sendo grande parte das demandas do serviço absorvidas pela equipe de voluntários.

Segundo estudo de Amado (2020) no qual destacou a importância das PICS no contexto da atenção básica à saúde, abordando a atuação multiprofissional como sendo uma das características dessas práticas demonstrando que o cuidado em saúde deve ser construído a partir de diversas vertentes e de forma compartilhada para que dessa forma, seja possível contribuir para a descentralização do cuidado, e isso pode ser possível através do uso das PICS, ressignificando o cuidado e as forma de utilização dos serviços de saúde, assim como, essa mudança também pode ocorrer com os profissionais de saúde, que se beneficiam com as PICS e o autocuidado.

Pouco se sabe sobre o perfil dos profissionais que praticam as PICS, os dados disponíveis são insuficientes, pois a maioria delas pode ser realizada por profissionais da Estratégia de Saúde da Família (ESF), sem registro específico ou vínculo formal em PICS (Tesser,2018).

Além de ter uma equipe qualificada é um desafio implementação de serviços, pois exigem cada vez mais a utilização de ferramentas e tecnologias que facilitem a identificação dos principais problemas de saúde da comunidade e a definição de 
intervenções eficientes e eficazes. Neste sentido, o planejamento, a programação e a avaliação das ações de saúde são fundamentais (Farias, 2018).

Diante do exposto nos deparamos com o seguinte questionamento: Qual a percepção dos terapeutas que atuam no LAPICS/UFRN sobre o atendimento de Harmonização Energética Emergencial desenvolvido no serviço?

É, portanto, necessário que haja uma equipe multiprofissional especializada no atendimento de HEE em todas as dimensões, garantindo-lhe o bem-estar e respeito à sua dignidade e o cuidado integral. A busca por subsídios para melhorar a organização do HEE levou os autores à realização deste estudo que teve como objetivo conhecer a percepção dos profissionais sobre o atendimento de Harmonização Energética Emergencial de um serviço de práticas integrativas e complementares em saúde.

\section{Metodologia}

Pesquisa qualitativa que utilizou como referencial metodológico a Pesquisa Convergente Assistencial (PCA), que apresenta cinco fases: concepção, de instrumentação, de perscrutação, de análise e de interpretação. Na fase de concepção estão contemplados objetos do estudo, objetivos e referencial teórico. Na fase de instrumentação, a descrição dos procedimentos de coleta de dados, dentre eles o local do estudo, os participantes e os métodos de coleta de dados. Na fase de perscrutação descrevese como os dados serão coletados. E, por último, como serão analisados e interpretados os dados e os cuidados com o rigor ético da pesquisa (Tretine, 2018).

O estudo teve como cenário o Laboratório de Prática Integrativas e Complementares da UFRN (LAPICS/UFRN), em especial o atendimento de HEE. O laboratório é vinculado ao Departamento de Saúde Coletiva da UFRN e funciona como um serviço especializado no atendimento em PICS, em situações de não pandemia, sua rotina diária atende em média 300 pessoas por semana, onde parte dessas pessoas passa pelo atendimento de HEE.

Adotou-se como critério de inclusão os profissionais atuantes no atendimento de HEE (terapeutas voluntários e servidores efetivos da UFRN). Excluíram-se os profissionais afastados do exercício profissional no período de coleta dos dados por motivo de férias ou licenças.

A coleta de dados ocorreu entre os meses de abril a junho de 2021, por meio de entrevista semiestruturada, realizada via Google Meet, cujo roteiro continha dados relacionados às características dos participantes, como: idade, sexo, nível de formação, naturalidade, tempo de atuação no campo da PICS, área de atuação no campo da PICS e tempo de atuação no atendimento de HEE e 05 questões norteadoras: Quais sentidos as práticas integrativas tem para você? Fale sobre a sua experiência com as práticas do Reiki e da Massagem? Para você qual a importância do atendimento de HEE? Fale sobre dificuldades e fragilidades do atendimento de HEE. Você teria alguma sugestão para melhoria do atendimento de HEE? As entrevistas foram individuais, gravadas com o consentimento prévio dos participantes, posteriormente transcritas, e com duração média de 30 minutos. Os participantes assinaram o Termo de Consentimento Livre e Esclarecido e, a fim de se manter o anonimato, foram identificados com a letra $\mathrm{T}$ de Terapeuta e números subsequentes, conforme a ordem em que a coleta de dados foi realizada, por exemplo: T1, T2... O término da coleta de dados ocorreu quando constatada a saturação dos dados com material suficiente para conhecer o objeto de investigação.

Para organização e análise dos dados optou-se pelo método do Discurso do Sujeito Coletivo (DSC) (Lefèvre \& Lefèvre, 2003). Esse método compreende quatro figuras metodológicas: Expressões Chave (ECH), que revelam a essência do conteúdo dos depoimentos; as Ideias Centrais (IC), que indicam o sentido ou a expressão linguística de um depoimento analisado e de cada conjunto de ECH de mesmo sentido ou sentido complementar que irão compor, posteriormente, o DSC; Ancoragem (AC), que compreende pressupostos, princípios, hipóteses e teorias que dão sustentação às expressões chave, e o DSC, que é um discurso síntese redigido na primeira pessoa do singular, com ECH que têm IC ou AC semelhantes ou complementares (Barreto 
et. Al, 2019). Para esse estudo, foram utilizadas 03 figuras metodológicas: ideias centrais, expressões chave e discurso do sujeito coletivo.

Os depoimentos coletados foram metodologicamente tratados por meio do software DSCsoft20. Nessa ferramenta, a dimensão qualitativa se expressa no DSC e a quantitativa na frequência de compartilhamento de discursos entre indivíduos, ou seja, discursos com a mesma IC. Portanto, depois de transcritas e digitadas todas as entrevistas, o software auxiliou a operacionalização em categorias, a elaboração do discurso, assim como a produção dos relatórios quantitativos, o que fornece o percentual de indivíduos que contribuíram com suas expressões chave relativas às ideias centrais.

\section{Resultados}

Dos 27 profissionais que atuam no atendimento de HEE, foram entrevistados 10 profissionais, a maioria pertencia ao gênero feminino (86\%), natural de Natal-RN (72\%), na faixa etária 30-39 anos (36\%), nível de formação com graduação completa $(36 \%)$, pertencentes às categorias profissionais de enfermeiros (22\%) e psicólogos (22\%).com tempo de atuação no campo das PICS de 03 anos (43\%), tempo de atuação no atendimento de HEE de 3 anos (36\%) e área de atuação predominante nas práticas do Reiki e massagem (98\%).

A partir da primeira pergunta: Quais sentidos às práticas integrativas tem para você? emergiram duas categorias a partir dos IC selecionados e seus respectivos DSC.

O quadro abaixo apresenta os discursos dos participantes sobre quais sentidos as práticas integrativas representam para eles.

Quadro 1- Sentidos das práticas integrativas.

\begin{tabular}{|c|c|c|}
\hline $\begin{array}{c}\text { IDEIAS } \\
\text { CENTRAIS } \\
\text { (ICs) }\end{array}$ & CATEGORIAS & $\begin{array}{c}\text { DISCURSO DO SUJEITO COLETIVO } \\
\text { (DSC) }\end{array}$ \\
\hline $\begin{array}{l}\text { - A relação com as práticas } \\
\text { integrativas é bem especial; } \\
\text { - Busca pela melhoria de } \\
\text { saúde; } \\
\text { - Gratidão em trabalhar com } \\
\text { as práticas integrativas; } \\
\text { - Práticas integrativas como } \\
\text { uma relação de amor e fé; }\end{array}$ & $\begin{array}{c}\text { Relação especial } \\
\text { com as PICS } \\
\text { (Categoria A) }\end{array}$ & $\begin{array}{l}\text { Minha relação com as práticas integrativas é bem especial e eu acho que tem } \\
\text { uma relação com toda minha história. Tinha algo que me chamava, assim mais } \\
\text { natural selvagem. Quando eu trabalho com as PICS isso também me ajuda, como eu } \\
\text { sinto que ajuda o Serciente, é uma troca e eu aconselho a todos que precisarem e até } \\
\text { não sintam que estão precisando, façam busquem a melhoria de saúde. Acabei vendo } \\
\text { no papel de cuidador em práticas integrativas uma excelente oportunidade de me } \\
\text { expressar, de fazer uma coisa que eu sentia vocação, que é cuidar. As PICS } \\
\text { representam uma forma de você se autodesenvolver, de promover a nossa própria } \\
\text { saúde, também traz um equilíbrio mental, físico, emocional e espiritual em todos os } \\
\text { sentidos. É uma gratidão e eu me sinto muito bem. }(T 1, T 2, T 3, T 5, T 7, T 9)\end{array}$ \\
\hline 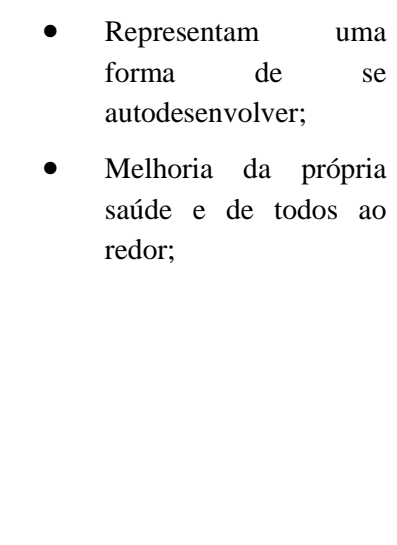 & $\begin{array}{c}\text { Relação do } \\
\text { Serciente, terapeuta } \\
\text { e as Práticas } \\
\text { Integrativas } \\
\text { (Categoria B) }\end{array}$ & $\begin{array}{l}\text { A relação do serciente com o terapeuta integrativo é bem interessante. Eu já } \\
\text { conhecia algumas práticas e fiz cursos dentro do LAPICS, aí quando eu vi a } \\
\text { possibilidade que a gente poderia cuidar do outro de uma forma muito melhor, de } \\
\text { uma forma integral, visando o emocional, mental, físico e energético, eu me } \\
\text { apaixonei. Comecei a fazer cursos, acabei fazendo uma imersão nelas. Veio vontade } \\
\text { de compartilhar com as outras pessoas e contribuir para outras pessoas, me ajuda } \\
\text { muito quando estou atendendo uma pessoa também estou trabalhando junto. Estou } \\
\text { aprendendo com aquelas pessoas e quando eu vejo os resultados nelas eu fico } \\
\text { superfeliz, meu coração fica feliz. Isso foi importante para minha própria melhora e } \\
\text { para ajudar a todos ao meu redor. } \\
\text { Pessoalmente tem tudo a ver comigo, aquilo que acredito, que a gente pode } \\
\text { estar contribuindo para um mundo melhor e para uma saúde mental, uma sociedade } \\
\text { mais equilibrada emocionalmente. (T4, T6, T8, T10) }\end{array}$ \\
\hline
\end{tabular}


Os discursos apresentados destacam os sentidos das práticas integrativas pa

ra os participantes e abordam a relação dessas práticas como sendo uma relação especial, além disso, destacam a importância delas na relação terapeuta-serciente.

Em relação à segunda pergunta: Fale sobre a sua experiência com as práticas do Reiki e da Massagem? dessa pergunta emergiu o seguinte discurso, a partir dos ICs destacados.

O Quadro abaixo apresenta os discursos dos participantes com relação a experiência quanto as práticas do Reiki e da massagem.

Quadro 2- Experiência com as Práticas do Reiki e massagem.

\begin{tabular}{|c|c|}
\hline $\begin{array}{c}\text { IDEIAS } \\
\text { CENTRAIS } \\
\text { (ICs) }\end{array}$ & $\begin{array}{c}\text { DISCURSO DO SUJEITO COLETIVO } \\
\text { (DSC) }\end{array}$ \\
\hline 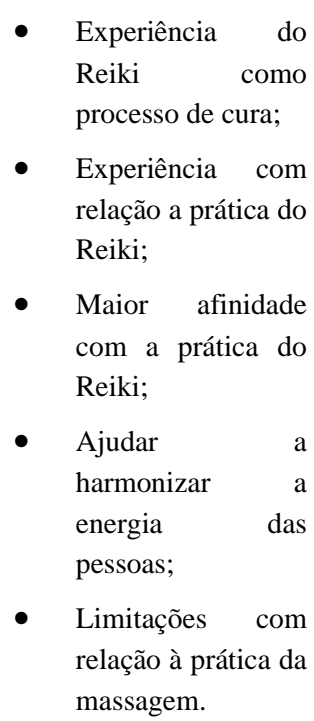 & $\begin{array}{l}\text { Na verdade, as duas são maravilhosas. A prática do Reiki, que era o que eu mais costumava utilizar na sala do } \\
\text { Emergencial, tem essa troca de energia e carinho, de amor acontece muito, uma relação bem interessante que a } \\
\text { gente vê que tem eficácia no processo de cura e não só de tratamento. A prática integrativa a gente não consegue } \\
\text { explicar, mas ela acontece e a gente consegue sentir. eu já fazia uma prática um pouco parecida que era do passe } \\
\text { magnético na Casa Espírita, que é um pouco parecida com o Reiki. Sabe doação ou troca de energias né. Desse } \\
\text { fluxo de energia. E sempre me senti bem à vontade de fazer isso. A gente vai evoluindo a cada serciente que } \\
\text { recebe, a gente vai evoluindo. Energia e vai só ajudando a pessoa a harmonizar a energia dela. A massagem } \\
\text { também é uma prática emergencial, ela exige um pouco mais da pessoa que vai aplicar, para quem vai receber é } \\
\text { só maravilha, mas para quem vai aplicar não. Tudo vai para o corpo, tudo, quando chega no corpo porque já } \\
\text { estava aqui na mente, então a parte boa da massagem é essa, você relaxa e é possível fazer e depois é possivel } \\
\text { associar com o Reiki para dissipar esse tipo de sensação que está ali no corpo né. Uma coisa que eu acho negativo } \\
\text { na massagem, não é que é negativo, mas que exige um certo cuidado e com relação à questão e éticas, pois existem } \\
\text { alguns contextos que impeçam que a gente tenha prática, pois pode ser que a pessoa não seja receptiva a essa } \\
\text { prática, mas enfim eu me sinto muito bem podendo colaborar com a saúde integrativa, integral e com SUS também. } \\
\text { (T1, T2, T3, T4, T5, T6, T7, T8, T9, T10). }\end{array}$ \\
\hline
\end{tabular}

Fonte: Dados da pesquisa.

Observa-se no discurso a experiência quanto as práticas do Reiki e da massagem, destacando a relação com cada prática, onde observa-se a maior afinidade dos participantes com a prática do Reiki e o relato de algumas limitações quanto a prática da massagem.

Em relação à terceira pergunta :Para você qual a importância do atendimento de HEE? da qual emergiram duas categorias de ideais centrais e seus respectivos DSC.

O Quadro abaixo apresenta os discursos sobre a importância do atendimento de Harmonização Energética Emergencial. 
Quadro 3 - Importância do atendimento de Harmonização Energética Emergencial.

\begin{tabular}{|c|c|c|}
\hline $\begin{array}{c}\text { IDEIAS } \\
\text { CENTRAIS } \\
\quad(\text { ICs })\end{array}$ & CATEGORIAS & $\begin{array}{c}\text { DISCURSO DO SUJEITO COLETIVO } \\
\text { (DSC) }\end{array}$ \\
\hline $\begin{array}{l}\text { - auto desenvolvimento } \\
\text { para o terapeuta; } \\
\text { - Utilização de diversas } \\
\text { vertentes do cuidado; } \\
\text { - O Reiki emergencial é } \\
\text { muito gratificante }\end{array}$ & $\begin{array}{l}\text { Autodesenvolvimento } \\
\text { para o terapeuta } \\
(\text { Categoria A) }\end{array}$ & $\begin{array}{l}\text { Então ali a gente se autodesenvolve, a gente consegue ajudar a cuidar do outro } \\
\text { enquanto a gente se cuida também. Aquele Reiki emergencial para mim é muito } \\
\text { gratificante. O Reiki me ajudou muito a sair de mim, como pessoa, gosto de me } \\
\text { doar. Socialmente é um trabalho extremamente relevante, porque você atendendo } \\
\text { a uma parcela, todo mundo sem distinção lá, politicamente, falando também tem } \\
\text { um peso gigantesco aí em políticas públicas que isso pode abrir para cada posto } \\
\text { desse. cientificamente nem se fala porque é um laboratório né. Então, ali é um } \\
\text { laboratório onde você de fato vai fazer todos esses testes, para analisar, para } \\
\text { poder cruzar. Ele é o abre portas. (T2, T4, T5, T7). }\end{array}$ \\
\hline $\begin{array}{l}\text { - Satisfação em ver a } \\
\text { satisfação do outro; } \\
\text { - A harmonização como } \\
\text { ferramenta para o } \\
\text { reequilíbrio energético; }\end{array}$ & $\begin{array}{c}\text { Promoção do bem-estar } \\
\text { do serciente } \\
\text { (Categoria B) }\end{array}$ & $\begin{array}{l}\text { É uma satisfação ver a satisfação do outro, isso é muito bom. quando a pessoa } \\
\text { está em um momento de uma crise muito grande ou de alguma certa perturbação, } \\
\text { aquele processo que a gente faz lá, aquele protocolo do emergencial, eu acho } \\
\text { muito bom por isso, dá aquela primeira acalmada, tira essa camada que está mais } \\
\text { por cima para poder adentrar mais com outras técnicas sabe, quando a gente faz } \\
\text { essa parte emergencial de harmonização, de equilíbrio estabiliza um pouco e eu } \\
\text { posso vir com outras práticas. Estamos ali auxiliando aquele serciente e sabemos } \\
\text { o quanto é importante, ver a gratidão deles, de auxiliar naquele momento, de } \\
\text { saber que ele está saindo bem após aquela sessão de Reiki. E por mais que seja } \\
\text { uma sala de harmonização emergencial, muitas pessoas iam para lá, porque } \\
\text { viram que sai resultado de lá daquela sala. Eu acho que é muito importante essa } \\
\text { prática e eu gostaria de ver mais pessoas tendo acesso a ela. (T1, T3, T6, T8, T9, } \\
\text { T10). }\end{array}$ \\
\hline
\end{tabular}

Fonte: Dados da pesquisa (2021).

Nos discursos é importante observar a importância do atendimento de HEE como uma ferramenta para o autodesenvolvimento do terapeuta e além disso, observa-se que esse tipo de atividade pode ser utilizada como estratégia de promoção do bem-estar do serciente.

Em relação à quarta pergunta: Aponte as dificuldades e fragilidades do atendimento de HEE, da qual emergiram duas categorias a partir das ideias centrais e seus respectivos DSC.

O Quadro abaixo destaca os discursos referentes as dificuldade e fragilidades presentes no atendimento de HEE, conforme a percepção dos terapeutas que atuam no serviço. 
Quadro 4 - Dificuldades e fragilidades do atendimento de Harmonização Energética Emergencial.

\begin{tabular}{|c|c|c|}
\hline $\begin{array}{c}\text { IDEIAS } \\
\text { CENTRAIS } \\
\text { (ICs) }\end{array}$ & CATEGORIAS & $\begin{array}{c}\text { DISCURSO DO SUJEITO COLETIVO } \\
\text { (DSC) }\end{array}$ \\
\hline $\begin{array}{ll}\text { - } & \text { dificuldade e } \\
\text { fragilidades do } \\
\text { atendimento; } \\
\text { - } & \text { estrutura física não } \\
\text { é a melhor } \\
\text { possível; } \\
\text { - } \\
\text { Algumas coisas } \\
\text { poderiam ser } \\
\text { automatizadas }\end{array}$ & $\begin{array}{c}\text { Estrutura física e } \\
\text { fluxo } \\
\text { (Categoria A) }\end{array}$ & $\begin{array}{l}\text { O ambiente é adequado, mesmo assim, seria bom que o LAPICS tivesse um ambiente maior } \\
\text { e um fluxo diferenciado, na minha opinião ele já se tornou pequeno demais para procura. } \\
\text { Algumas dificuldades devido a questão de que a sala da harmonização ser coletiva, então } \\
\text { às vezes a gente precisava conversar, por mais que não tivesse esse intuito de conversar } \\
\text { com o Serciente, mas a gente necessitava conversar com eles e acabava atrapalhando a } \\
\text { terapia do terapeuta do lado, uma outra questão é comunicação e do registro das atividades } \\
\text {, no preenchimento do BPA, tinha essa dificuldade do fluxo de informação, o que levar o } \\
\text { que trazer e como coletar, já que algumas informações a gente precisava estar com o } \\
\text { serciente para perguntar e entrava nessa questão de atrapalhar a terapia ao lado. Não tem } \\
\text { como fornecer privacidade ao usuário, fazer um acolhimento adequado, ter uma conversa } \\
\text { adequada com ele para checar de fato as necessidades e dentro nosso limite acolher, o que } \\
\text { pode ser realizado. Às vezes os sercientes buscavam a harmonização emergencial e não } \\
\text { conseguiam, porque um terapeuta de Reiki leva de } 30 \text { a } 40 \text { minutos em uma sessão e às } \\
\text { vezes tinham os desfalques na escala. A forma dos registros ainda acontece de forma muito } \\
\text { braçal, tem algumas coisas que poderiam ser automatizadas. (T1, T2, T3, T4, T6, T9, T10) }\end{array}$ \\
\hline $\begin{array}{l}\text { - Eu fui muito bem } \\
\text { amparada ali; } \\
\text { - Eu nunca tive } \\
\text { muita dificuldade. }\end{array}$ & $\begin{array}{l}\text { Sem dificuldades } \\
\text { e fragilidades } \\
(\text { Categoria } B)\end{array}$ & $\begin{array}{l}\text { Assim, lá para mim foi uma casa e a família, eu fui muito bem amparada sim. Estava aberta } \\
\text { a aprender, a perguntar, às pessoas lá, todos eles sem tirar nenhum estavam lá aptos a } \\
\text { querer realmente passar a ensinar. eu gosto muito dali. Eu considero o Reiki uma terapia } \\
\text { que você não precisa de uma infraestrutura mega, então eu nunca tive muita dificuldade. } \\
(\mathrm{T} 5, \mathrm{~T} 8) \text {. }\end{array}$ \\
\hline
\end{tabular}

Fonte: Dados da pesquisa (2021).

Os discursos representados acima destacam as dificuldades e fragilidades referentes ao atendimento de HEE, apresentando questões relacionadas a estrutura física e o fluxo de atendimento do serviço.

Em relação à quarta pergunta: Você teria alguma sugestão para melhoria do atendimento de HEE? da qual emergiram três categorias de ideias centrais e seus respectivos DSC.

O Quadro abaixo representa os discursos onde são propostas as sugestões de melhorias para o atendimento de HEE. 
Quadro 5 - Sugestões de melhorias para o atendimento de Harmonização Energética Emergencial.

\begin{tabular}{|c|c|c|}
\hline $\begin{array}{c}\text { IDEIAS } \\
\text { CENTRAIS } \\
\text { (ICs) }\end{array}$ & CATEGORIAS & $\begin{array}{l}\text { DISCURSO DO SUJEITO COLETIVO } \\
\text { (DSC) }\end{array}$ \\
\hline $\begin{array}{l}\text { - melhoria da estrutura } \\
\text { física e do acolhimento; } \\
\text { atendimento em salas } \\
\text { individuais; } \\
\text { - A sala ser destinada } \\
\text { apenas para a prática do } \\
\text { Reiki; } \\
\text { - monitorar o fluxo. }\end{array}$ & $\begin{array}{c}\text { Melhoria da } \\
\text { estrutura física e } \\
\text { fluxo } \\
\text { (Categoria A) }\end{array}$ & $\begin{array}{l}\text { A gente tem que obedecer a esse fluxo, quem está ali tem que colaborar com esse } \\
\text { fluxo, eu acho que o fluxo que era estava bom. ter essa classificação que oriente esse } \\
\text { fluxo. Alguém ficaria responsável por fazer essa rota de levar o serciente para } \\
\text { harmonização. Deveria ter uma mínima conversa tem que ter como o terapeuta na } \\
\text { sala, para saber o que ele tem, para saber o que irá realizar. Já com relação à } \\
\text { estrutura física seria bom a aquisição tanto de maca, como de divisórias biombos. } \\
\text { Também material para conforto do paciente precisaria de um melhor isolamento de } \\
\text { som da sala para que essa pessoa não fosse perturbada durante a sua sessão e que } \\
\text { não possa prender concentração. Eu prefiro que fosse individual, certo, que fosse em } \\
\text { salas individuais porque é um momento muito individual, sabe, muito íntimo também. } \\
\text { tudo é uma questão de estrutura, eu sempre achei que a sala do Reiki deveria ser só } \\
\text { do Reiki. (T1, T2, T3, T5, T6) }\end{array}$ \\
\hline 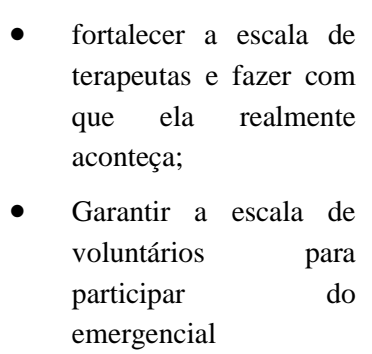 & $\begin{array}{l}\text { Fortalecimento da } \\
\text { escala } \\
\text { terapeutas } \\
\quad(\text { Categoria B) }\end{array}$ & $\begin{array}{l}\text { Essa questão da escala de fortalecer a escala e fazer com que ela realmente } \\
\text { acontecesse, eu vou sugerir em relação aos cursos, que eu acho que a gente tinha que } \\
\text { ter um controle maior depois do curso naquela parte da prática garantir a escala dos } \\
\text { voluntários para quem realmente participem do Reiki emergencial. (T1, T4, T8, T9, } \\
\text { T10) }\end{array}$ \\
\hline $\begin{array}{l}\text { Reuniões para buscar } \\
\text { melhorias; } \\
\text { - Encontros para o } \\
\text { aprimoramento. }\end{array}$ & $\begin{array}{l}\text { Reuniões de equipe } \\
\text { (Categoria } \mathrm{C})\end{array}$ & $\begin{array}{l}\text { Acredito que deve existir mais encontros para a gente se organizar, falar e debater } \\
\text { algumas coisas, ajustar as coisas essenciais a serem ajustadas. É sempre bom ter } \\
\text { reuniões para buscar melhoria. Gostaria que fossem retomadas aquelas as práticas } \\
\text { que a professora tinha, que eu participei, onde a gente foi fazer as mandalas, outra } \\
\text { vez eu tive a grande oportunidade de fazer a meditação ao ar livre na praia, mas } \\
\text { assim alguns minicursos de autodesenvolvimento, autoconhecimento, tipo CNV que é } \\
\text { comunicação não violenta. E assim ter reuniões com esse novo modo de reunião } \\
\text { virtual. (T1, T2, T3, T9) }\end{array}$ \\
\hline
\end{tabular}

Fonte: Dados da pesquisa (2021).

Os discursos apresentados no quadro 5, apontam as sugestões de melhorias para o atendimento de HEE, apresentando como sugestões a melhorias da estrutura física e fluxo do serviço, fortalecimento da escala de terapeutas e promoção de reuniões de equipe.

\section{Discussão}

Os discursos dos sujeitos da pesquisa trazem os sentidos das PICS para os terapeutas onde essas práticas são apontadas como sendo algo especial tanto para o terapeuta como para o Serciente, pois tanto os profissionais quanto os usuários buscam as PICS como forma de melhorar a saúde e partir desses resultados disseminar o aprendizado para cuidado da saúde do outro (Aguiar,2019).

$\mathrm{O}$ atendimento de HEE acontece no serviço devido ao esforço conjunto dos profissionais que lá atuam, pois, a maioria dos terapeutas exercem suas atividades de forma voluntária, destinando parte do seu tempo para atender no LAPICS/UFRN. 
O esforço para que essas práticas aconteçam, geralmente parte dos profissionais de saúde com engajamento nas PICS, estimulados pelo objetivo de consolidar uma concepção de cuidado divergente do modelo preponderante, entendendo que há práticas que podem se destacar quanto aos resultados, tornando-se parte de um novo processo de implementação de alternativas para a promoção da saúde, que compreendem o ser humano em sua totalidade (Soares, 2020).

No que diz respeito à experiência quanto à prática do Reiki e da massagem, os terapeutas destacam a afinidade com a prática do Reiki devido essa prática abranger o corpo, a mente e a alma, procurando pôr esses elementos do indivíduo em equilíbrio. Durante um tratamento de Reiki, a mente e o processo do pensamento relaxam, proporcionando uma consciência emocional e mental maior dos processos internos. Em geral, as pessoas se sentem mais lúcidas, podendo detectar e anular crenças negativas, a respeito de si mesmo e de outras pessoas (Federazzi, 2017).

Corroborando com o estudo de Federizzi, observa-se que quando se trata da experiência dos profissionais quanto às práticas do Reiki e da massagem, nota-se uma afinidade maior com a terapia Reiki e isso fica evidente nos discursos.

Com relação a massagem, são apontados os benefícios, assim como algumas limitações, visto que a massagem exige disposição física do terapeuta e conhecimento quanto às contraindicações de aplicação da técnica e implicações éticas.

A prática da massagem ajuda o relaxamento, a sensação de prazer, a ultrapassar problemas físicos, a libertar bloqueios emocionais, a amenização da dor, entre outros (Alves, 2015).

Quando se fala na importância do atendimento de HEE, são destacadas pelos participantes questões voltadas para o autodesenvolvimento do terapeuta e promoção do bem-estar do Serciente. Eles relatam em seus discursos, os benefícios que essa atividade promove tanto para o profissional quanto para o usuário.

As técnicas utilizadas nesse tipo de atendimento tem caráter preventivo e age na causa dos problemas, demonstrando desfecho satisfatório ao ser utilizada em casos de ansiedade, depressão, insônia, medo, pânico, nas situações com sintomatologia dolorosa presente e em outras situações que possuem indicação para uso, além disso, elas permitem a humanização do cuidado, uma vez que são obedecidos os princípios de acolhimento, escuta, confiança, avaliação e possível encaminhamento adequado a outros profissionais de saúde quando necessário, visando resolução da demanda apresentada pelos pacientes (Spezzia, 2018).

Para o terapeuta do Reiki, a prática tem um papel importante no desenvolvimento da consciência do autocuidado, pois inicialmente para se aplicar Reiki em outras pessoas é necessário passar por um processo de purificação energética de 21 dias. Isso leva um praticante de Reiki a desenvolver essa consciência que acaba disseminando e contagiando todos ao seu redor, criando, assim, de maneira sutil, a consciência coletiva do autocuidado (Motta, 2015).

No que diz respeito às dificuldades e fragilidades no atendimento de HEE os participantes apontam fatores relacionados à estrutura física e ao fluxo do serviço, devido a grande demanda por atendimentos e carência de um fluxo que atenda às necessidades do serviço. Além disso, apontam questões voltadas para formação profissional e fortalecimento da equipe.

Estudos destacam uma restrição do acesso às PIC, com uma alta demanda reprimida, principalmente em serviços no nível secundário, ou seja, ambulatórios especializados. Além disso, questões voltadas à formação em PICS, observa-se que a maioria dos cursos é ofertada por instituições de cunho privado, dessa forma, a ausência de investimento na formação de profissionais para as PICS dificulta o aumento da sua oferta na saúde pública. Por outro lado, os profissionais que possuem formação na área de PICS nem sempre têm acesso a espaço físico e materiais para executar suas ações; muitas vezes, não possuem nem autorização para fazê-las. (Aguiar,2019 \& Habimorad, 2018).

Como sugestão para melhoria do atendimento de HEE surgiram discursos relacionados à melhoria da estrutura física e fluxo, fortalecimento da escala de terapeutas e promoção de reuniões de equipe.

O investimento na qualificação dos profissionais, estudos e fomento na área é baixo, todavia, independente de recurso indutor, os municípios brasileiros oferecem PIC para o cuidado à saúde, a maioria destes com recursos próprios. Para uma melhor formação em saúde, profissionais e gestores necessitam de maior capacitação, porque não se sentem aptos para o trabalho no 
âmbito das práticas humanizadoras do cuidado. Um modelo de atenção que inclui as PICS promove a humanização, diminui custos com medicamentos e serviços de alta complexidade. Para tanto, é preciso. impulsionar a inclusão e o desenvolvimento de espaços acadêmicos para a formação nesta área, além disso, é urgente a necessidade de uma política de incentivo financeiro para que sejam instituídas, de fato, as PICS no SUS (Dalmolin, 2020 \& Oliveira, 2017).

\section{Considerações Finais}

O atendimento de Harmonização Energética Emergencial é uma atividade importante em meio às práticas realizadas no LAPICS/UFRN, pois muitas vezes funciona como o primeiro contato do Serciente com essas práticas. A utilização do Reiki e da Massagem promovem o reequilíbrio do bem-estar do Serciente, assim como, viabiliza o autodesenvolvimento do terapeuta que executa essas práticas.

Os discursos presentes nesse trabalho, destacaram a importância da HEE para os profissionais que atuam nesse serviço, despertando a reflexão a respeito do processo, apontando as oportunidades de crescimento dos profissionais, destacando também as fragilidades presentes no serviço, assim como, apontando sugestões de melhoria para que essa atividade seja desenvolvida da melhor forma.

É importante conhecer a percepção desses terapeutas, pois isso estimula o processo de avaliação das atividades realizadas, assim como, faz com que esses profissionais se sintam pertencentes ao processo de trabalho realizado no atendimento de HEE e dessa forma seja possível realizar um serviço que atenda as demandas apresentadas pelos Serciente, visando sempre o cuidado de forma integral.

Como limitações do estudo, têm-se as dificuldades de acesso aos meios digitais, como internet, ferramentas de encontros virtuais, entre outros, por parte dos entrevistados.

O estudo ainda apontou lacunas quanto à formação profissional, acesso e investimentos no campo das PICS, sendo necessária a ampliação dos investimentos em PICS, assim como estímulo à formação de profissionais capacitados para executarem tais práticas.

\section{Referências}

Aguiar, J., Kanan, L. A., \& Masiero, A. V. (2020). Práticas Integrativas e Complementares na atenção básica em saúde: um estudo bibliométrico da produção brasileira. Saúde em Debate, 43, 1205-1218.

Alves, M. R. R., \& Silva, A. O. (2018). Guia informativo sobre práticas integrativas e complementares para pessoa idosa na atenção à saúde. Revista de Pesquisa: Cuidado é fundamental online, 10(2), 313-316.

Amado, D. M., Barbosa, F. E. S., dos Santos, L. N. D., de Araújo Melo, L. T., Rocha, P. R. S., \& Alba, R. D. (2020). Práticas integrativas e complementares em saúde. Aps em revista, 2(3), 272-284.

Assis, W. C., Britto, F. R., de Oliveira Vieira, L., dos Santos, E. S., de Oliveira Boery, R. N. S., \& Duarte, A. C. S. (2018). Novas formas de cuidado através das práticas integrativas no sistema único de saúde. Revista Brasileira em Promoção da Saúde, 31(2).

Bezerra, D. P. A. (2019). Protocolo de acolhimento integrativo humanescente: um estudo de validação processual (Master's thesis, Brasil).

Brasília: Ministério da Saúde, 2006. 92 p. http://bvsms.saude.gov.br/bvs/publicacoes/pnpic.pdf Acesso em novembro de 2015.

Dalmolin, I. S., Heidemann, I. T. S. B., \& Freitag, V. L. (2019). Práticas integrativas e complementares no Sistema Único de Saúde: desvelando potências e limites. Revista da Escola de Enfermagem da USP, 53. Federizzi, D. S., Freitag, V. L., Petroni, S., Cosentino, S. F., \& Dalmolin, I. S. (2017). Efeitos da aplicação de reiki no cuidado ao usuário com hipertensão arterial sistêmica. Revista Enfermagem Atual In Derme, 83(21).

Faria, H. P. D., Campos, F. C. C. D., \& Santos, M. A. D. (2018). Planejamento, avaliação e programação das ações de saúde.

Habimorad, P. H. L., Catarucci, F. M., Bruno, V. H. T., Silva, I. B. D., Fernandes, V. C., Demarzo, M. M. P., ... \& Patricio, K. P. (2020). Potencialidades e fragilidades de implantação da Política Nacional de Práticas Integrativas e Complementares. Ciência \& Saúde Coletiva, 25, 395-405.

Kurebayashi, L. F. S., Turrini, R. N. T., Souza, T. P. B. D., Takiguchi, R. S., Kuba, G., \& Nagumo, M. T. (2016). Massagem e Reiki para redução de estresse e ansiedade: Ensaio Clínico Randomizado. Revista Latino-Americana de Enfermagem, 24. 
Research, Society and Development, v. 10, n. 12, e260101220511, 2021

(CC BY 4.0) | ISSN 2525-3409 | DOI: http://dx.doi.org/10.33448/rsd-v10i12.20511

Lefèvre, F., \& Lefèvre, A. M. C. (2003). O discurso do sujeito coletivo: um novo enfoque em pesquisa qualitativa; desdobramentos. In O discurso do sujeito coletivo: um novo enfoque em pesquisa qualitativa; desdobramentos (pp. 255-255).

Lei n. 10.933, de 17 de junho de 2021. Dispõe sobre a Política Estadual de Práticas Integrativas e Complementares (PEPIC) no âmbito da Rede de Serviços do Sistema Único de Saúde (SUS) no Estado do Rio Grande do Norte. Rio Grande do Norte. RN. http://diariooficial.rn.gov.br/dei/dorn3/docview.aspx?id_jor=00000001\&data=20210618\&id_doc=727178.

Lei n. 10.933, de 17 de junho de 2021. Dispõe sobre a Política Estadual de Práticas Integrativas e Complementares (PEPIC) no âmbito da Rede de Serviços do Sistema Único de Saúde (SUS) no Estado do Rio Grande do Norte. Rio Grande do Norte. RN.

Motta, M., \& de Barros, N. F. (2015). A aplicação de técnicas de imposição de mãos no estresse-ansiedade: revisão sistemática da literatura/The application of the technique of imposition of hands on stress-anxiety: a systematic literature review. Cadernos Brasileiros de Terapia Ocupacional, 23(2).

Oliveira, N. M. L. D., Hueb, M. F. D., \& Castro, S. S. D. (2015). Effect of classic massage in quality of life of university students. Fisioterapia em Movimento, $28,793-802$.

Prefeitura Municipal do Natal. SMS cria o Centro de Referência em Práticas Integrativas e Complementares. 2017. http://www.natal.rn.gov.br/noticia/ntc26245.html.

Sampaio, A. T. L., de Oliveira Rondon, G. M. A., \& Negrão, O. G. C. Laboratório de práticas integrativas e complementares em saúde-lapics na ufrn e no sus do rn: do sonho a realidade.

Soares, R. D., Pinho, J. R. O., \& Tonello, A. S. (2020). Diagnóstico situacional das Práticas Integrativas e Complementares na Atenção Primária à Saúde do Maranhão. Saúde em Debate, 44, 749-761.

Spezzia, S., \& Spezzia, S. (2018). O uso do Reiki na assistência à saúde e no Sistema Único de Saúde. Revista de Saúde Pública do Paraná, 1(1), 108-115. Tesser, C. D., Sousa, I. M. C. D., \& Nascimento, M. C. D. (2018). Práticas integrativas e complementares na atenção primária à saúde brasileira. Saúde em debate, $42,174-188$.

Trentini, M., Paim, L., \& Silva, D. M. G. V. D. (2018). O método da pesquisa convergente assistencial e sua aplicação na prática de enfermagem. Texto \& Contexto-Enfermagem, 26. 